\title{
Prevalence and acceptance of face mask practice among individuals visiting hospital during COVID-19 pandemic: Observational study.
}

Gobi Hariyanayagam Gunasekaran ${ }^{1}$, Sera Selvanthansundram Gunasekaran ${ }^{2}$, Shargunan Selvanthan Gunasekaran ${ }^{3}$, Fouzia Hanim Bt Abdul Halim ${ }^{1}$

1. Oncology Pharmacy, Hospital Seri Manjung, 32040 Seri Manjung, Perak, Malaysia.

2. Medical Officer, Hospital Seri Manjung, 32040 Seri Manjung, Perak, Malaysia.

3. Dental Officer, Manjung District Dental Clinic, 32000 Sitiawan, Perak, Malaysia.

\begin{abstract}
Background

The COVID-19 transmission has been established to occur through respiratory droplets from coughing and sneezing. Health agencies have strongly recommended the use of facemask as a precaution from cross-transmission.
\end{abstract}

\section{Objective}

This study investigated the prevalence of facemask use among visitors to the hospital. This study also investigated the demographic factors contributing to unacceptable facemask practice.

\section{Setting}

This prospective observational study was done among hospital visitors to a district specialist hospital during COVID-19 pandemic outbreak. 


\section{Methods}

Individuals entering through dedicated entry point were observed for the type, category and practice of wearing personal protective equipment. Inclusion criteria for this study were any individual's $\geq 2$ years old entering the treatment facility from selected entry points. Patients were categorized into two groups of acceptable and unacceptable facemask practice. The Pearson chi-square was used to test for differences in investigated variables in the univariate setting and Binary Logistic regression model was used in the multivariate setting.

\section{Main outcome measure}

Prevalence, acceptance practice and odds ratio of unacceptance of facemask use.

\section{Results}

Among 1652 individuals included in the final analysis, 1574 (96.9\%) was observed wearing facemask with 1269 (72.0\%) of individuals worn medical-grade facemask. However, among them, only 1397 (88.8\%) individuals' facemask practice was acceptable while the reaming 177 (11.2) individuals were perceived with unacceptable facemask practice. Male individuals, Malay ethnic and high risk age group are 1.47 times (Odds Ratio: OR=1.47; 95\% CI, 1.062.06; $\mathrm{p}=.023), 2.18$ times $(\mathrm{OR}=2.18 ; 95 \% \mathrm{CI}, 1.55-3.08 ; \mathrm{p}<.001)$ and 1.99 times $(\mathrm{OR}=2.18$; 95\% CI, $1.42-2.77 ; \mathrm{p}<.001)$ more likely to exhibit unacceptable facemask practice respectively.

\section{Conclusion}

Extensive use of facemasks coupled with environmental hygiene measures is a public health strategy which can help to mitigate the COVID-19 epidemic impact. However, a targeted 
comprehensive strategy to improve compliance to proper facemask practice among the highrisk population is needed to achieve maximal protective benefit

\section{Keywords}

Covid-19, personal protective equipment, facemask, odds ratio, Malaysia

\section{Introduction}

In late December 2019, an initial clusters of pneumonia cases of unknown novel coronavirus disease (COVID-19; previously known as 2019-nCoV or SARS-CoV-2) was reported in Wuhan, China[1, 2]. By March 2020, the outbreak subsequently spread to more 26 countries worldwide which promoted the World Health Organization to declared the infection a pandemic, indicating significant public health emergency of international concern[3]. In general, COVID-19 is an acute systemic and respiratory disorders which appear after an incubation period of approximately 5.2 days with common symptoms such as fever, cough, fatigue, , sneezing, sore throat and sometimes accompanied by rhinorrhoea, headache, haemoptysis, diarrhoea, dyspnoea, and lymphopenia [[4-7]. Although the infection is selflimiting in $81 \%$ of the cases, $19 \%$ of the infection will require medical support with a 1.5 $3.6 \%$ fatality rate according to Clinical and epidemiological data from the China Centres for Disease Control and Prevention[8, 9].

As with other respiratory pathogens, including flu and rhinovirus, the transmission is believed to occur through respiratory droplets from coughing and sneezing[10, 11]. It is now concluded that sustained human-to-human transmission aided in the establishment of the COVID-19 epidemic $[12,13]$.Although the consensus of asymptomatic individuals transmitting the virus 
before symptoms develop seems to be inconclusive, a risk on transmission cannot be fully excluded $[8,14,15]$. This data suggests that the use of respiratory protection and isolation is the best way to contain this epidemic.

During the early stage of the outbreak ; graphic pictures of civilian, authorities and health care personnel wearing extensive personal protective equipment (PPE) were widely covered by media highlighting the importance hygiene barriers in preventing infection[16]. Once local epidemics begin, a substantial increase in the use of PPE both in community and healthcare settings were reported [17-19]. While there was consistency in the recommendation that symptomatic individuals and health care workers should use facemasks, discrepancies in practice were observed in the general population. A research group led by Feng $S$ et al have complied the conflicting recommendation by difference agencies ; For example, the western countries such as the United States, United Kingdom and Germany health authorities have advised against buying masks for use by healthy people while Asian countries such as China, South Korea and Japan have adopted a risk-based approach by distributing facemask to the general public[20]. This sudden uptake in the use of PPE especially facemasks by the general public exacerbates the global supply shortage of facemasks, risking supply constraints to both health-care workers and vulnerable population particularly those older than 65 years and immunocompromised individuals[21, 22] .

Ideally, basic PPE to such as facemasks should be available en masse, especially worn by vulnerable populations and people with underlying health conditions. However, the usage of facemask depends on the recommendation of local health authorities as well as the availability of the commercial product in the market. The facemask practice among real world general population is relatively unknown[23]. Understanding facemask usage among local community 
particularly among those visiting high risk area for cross-contamination such as hospital is one research area that may help to describe the prevalence of respiratory protective device used. The findings of this research could be used to improve strategic management for public health as well as managing Covid-19 pandemic in community setting.

\section{Aim of the study}

This study aims to investigate the prevalence and types of respiratory protective device (facemask) usage among individuals visiting hospital during Covid-19 pandemic .This study also aims to evaluate the acceptance of the facemask practice worn by individuals.

\section{Ethics Approval}

The ethical approval to conduct the study was obtained from the Medical Ethical Review Committee [MERC KKM. NIHSEC. P20-902(6)], Ministry of Health, Malaysia.

\section{Methods}

\section{Study setting}

For this study; patients, their companion or visitors entering the hospital will be all be referred to as individuals. This prospective observational study was conducted among individuals visiting Hospital Seri Manjung, Malaysia in April 2020. At the time of writing, this treatment facility practices preliminary screening (body temperature and respiratory symptoms) for visitors before entering the treatment facility with a separate entry point for visitors with respiratory symptoms and those without. The study subject for this study was selected from entry point without respiratory symptoms which provided a representative of the asymptomatic 
general population where the decision of wearing facemask is a matter of choice rather than a requirement.

\section{Inclusion and Exclusion}

Inclusion criteria for this study were any individuals entering the treatment facility from selected entry points (without respiratory symptoms). Exclusion criteria for this study were individuals less than 2 years old, visiting the emergency department, working at the treatment facility, individuals which are suspected of multiple entry and individuals who are exiting the treatment facility entrance.

\section{Data Variables}

Individual data were collected by visually observing the type of facemask used and evaluating the garbing practice among visitors entering into the treatment facility. The following demographic data were collected: patient's gender, age group and ethnicity while facemask data such as category and type of the product as well as garbing technique was recorded. Besides, the time of entrance to the facility was recorded. Gender was categorised as either male or female while patients ethnicity was categorised into Malay or Non-Malay to reflect population distribution[24]. The Visitors age group was recorded as either as children, adult or elderly which was done based on subject's facial and physical feature[25] . The age group was further categorised to low-risk age (children and adult) or high-risk age (elderly) group [2628]. Facemask usage classifies as either "Yes" when any type of respiratory protective device is worn or as "No" when the product is absent. The category of facemask used was described according to their class ; surgical facemask (2, 3 ply or any medical grade mask), respirators (all respirator Standard ; FFP1 \& P1, FFP2 \& P2, N95, N99 \& FFP3, P3 , N100 ), cloth or paper mask . The facemask was further categorized as medical-use (Surgical facemask and 
respirator) or non-medical use (cloth and paper mask).The acceptance level of facemask practice was recorded as acceptable (correct wearable method) or unacceptable (incorrect method). The reason for unacceptable practice was further described as well. Finally, the visit time was categorized to morning session (am until $12 \mathrm{pm}$ ) or evening session (1 pm until p.m.) to reflect the elective operational hour of the facility. Additionally, we also collected information on any other type of PPE such as glove, apron, hair cover or any other atypical used.

\section{Statistical analysis}

All demographic and categorical variables were presented as number (n) and percentage (\%). Pearson's chi-squared test was used to determine the statistically significant difference between the demographic characteristic between age group and the acceptance level of facemask practice. Simple logistic regression was used to screen the independent variable. Variables with $\mathrm{p}$ value $<0.25$ were included in the multivariate analysis. Binomial logistic regression test was applied to determine the contributing factor to unacceptable facemask garbing practice. Correlation matrix was checked for interaction between the variables. The Hosmer and Lemeshow test, Classification table and the Area under the curve was used to evaluate the model of good fit. The final model was presented with $95 \%$ confidence interval (CI) and its corresponding p-value. For all test Two-tailed p-value $<0.05$ was considered as statistically significant. All statistical analyses were performed using SPSS for Windows version 22.0 (SPSS Inc., Chicago, Illinois, USA).

\section{Result}

The 1652 individuals included in the final analysis compromised of 57.2\% (930) male and $42.8 \%$ (695) female subjects with 56.2\% (913) representation of Malay ethnic as well as $95.9 \%$ 
(1559) combination of adult and elderly, which is a good representation of the local population . As shown in Table 1, 1574 (96.9\%) of individuals had worn facemask. Among them 1269 (72.0\%) individuals worn medical grade facemask with a majority of them was wearing surgical type facemask (70.5\%). We also observed that $45(2.8 \%)$ individuals had at worn glove, however we did not observe any practice of using of hair cover, boot cover, apron/overall or any other types of atypical PPE among the study population.

\begin{tabular}{|c|c|c|}
\hline Demographic characteristics & Frequency $(n=1625)$ & Percent (\%) \\
\hline $\begin{array}{l}\text { Gender } \\
\text { Male } \\
\text { Female }\end{array}$ & $\begin{array}{l}930 \\
695\end{array}$ & $\begin{array}{l}57.2 \\
42.8\end{array}$ \\
\hline $\begin{array}{l}\text { Ethnic } \\
\text { Malay } \\
\text { Malay } \\
\text { Non-Malay } \\
\text { Chinese } \\
\text { Indian } \\
\text { Unknown }\end{array}$ & $\begin{array}{l}913 \\
342 \\
354 \\
16\end{array}$ & $\begin{array}{l}56.2 \\
21.0 \\
21.8 \\
0.9\end{array}$ \\
\hline $\begin{array}{l}\text { Age group } \\
\text { Low risk age group } \\
\text { Children } \\
\text { Adult } \\
\text { High risk age group } \\
\text { Elderly } \\
\end{array}$ & $\begin{array}{l}66 \\
1071 \\
488 \\
\end{array}$ & $\begin{array}{l}4.1 \\
65.9 \\
30.0 \\
\end{array}$ \\
\hline $\begin{array}{l}\text { Session of visit } \\
\text { Morning session } \\
\text { Afternoon session } \\
\end{array}$ & $\begin{array}{l}1211 \\
414\end{array}$ & $\begin{array}{l}74.5 \\
25.5\end{array}$ \\
\hline $\begin{array}{l}\text { Face Mask practice } \\
\text { Yes } \\
\text { No } \\
\end{array}$ & $\begin{array}{l}1574 \\
51\end{array}$ & $\begin{array}{l}96.9 \\
3.1 \\
\end{array}$ \\
\hline $\begin{array}{l}\text { Category Of face Mask } \\
\text { Did not wear face mask } \\
\text { Medical Grade } \\
\text { Surgical face mask } \\
\text { Respirator } \\
\text { Non-Medical Grade } \\
\text { Cloth mask } \\
\text { Paper mask } \\
\end{array}$ & $\begin{array}{l}51 \\
1145 \\
24 \\
285 \\
119\end{array}$ & $\begin{array}{l}3.1 \\
70.5 \\
1.5 \\
17.5 \\
7.3\end{array}$ \\
\hline
\end{tabular}


One of the main aim of the study was to investigate the prevalence of facemask practice among high-risk age (elderly) group. A significant relation was found between age group and the following demographic variables ; gender, ethnic, session of visit to facility and use of facemask .As shown in Table 2 ,More male (63.3\%) from high-risk age group were visiting treatment facility compared to male $(54.6 \%)$ from low-risk age group, $\chi 2(1)=10.56, p=0.001$ . As for ethnicity, higher number of non-Malay ethic (59.0\%) from high-risk age group were visiting treatment facility compared to non-Malay ethnic $(37.3 \%)$ from low-risk age group, $\chi 2(1)=65.47, \mathrm{p}<.001$. Although Higher proportion of individuals were expected during morning session, significantly more individuals (80.3\%) within high-risk age group are visiting the treatment at morning session compared to individuals (72.0\%) from low-risk age group , $\chi 2(1)=12.38, p<0.001$. As for the use of facemask, higher number of individuals $(98.8 \%)$ from high-risk were using facemask compared to individuals (96\%) from low-risk age group, $\chi 2(1)=8.36, p=0.004$. Similarly, higher number of individuals $(77.8 \%)$ from high-risk age group were using medical grade facemask compared to individuals $(72.8 \%)$ from low-risk age group, $\chi 2(1)=4.38, \mathrm{p}=0.036$.

Table 2 Demographic profile between low-risk and high-risk age group $(n=1625)$

\begin{tabular}{|c|c|c|c|c|c|}
\hline & \multicolumn{2}{|c|}{ Low-Risk (n=1137) } & \multicolumn{2}{|c|}{ High-risk(n=488) } & \multirow[t]{2}{*}{$P$ value } \\
\hline Demographic characteristic & Frequency & Percent $(\%)$ & Frequency & Percent $(\%)$ & \\
\hline $\begin{array}{l}\text { Gender } \\
\text { Male } \\
\text { Female }\end{array}$ & $\begin{array}{l}621 \\
516\end{array}$ & $\begin{array}{l}54.6 \\
45.4\end{array}$ & $\begin{array}{l}309 \\
179\end{array}$ & $\begin{array}{l}63.3 \\
36.7\end{array}$ & .001 \\
\hline $\begin{array}{l}\text { Ethnic } \\
\text { Malay } \\
\text { Non-Malay }\end{array}$ & $\begin{array}{l}713 \\
424\end{array}$ & $\begin{array}{l}62.7 \\
37.3\end{array}$ & $\begin{array}{l}200 \\
288\end{array}$ & $\begin{array}{l}41.0 \\
59.0\end{array}$ & $<.001$ \\
\hline $\begin{array}{l}\text { Session of visit } \\
\text { Morning session } \\
\text { Afternoon session } \\
\end{array}$ & $\begin{array}{l}819 \\
318 \\
\end{array}$ & $\begin{array}{l}72.0 \\
28.0\end{array}$ & $\begin{array}{l}392 \\
96\end{array}$ & $\begin{array}{l}80.3 \\
19.7\end{array}$ & $<.001$ \\
\hline $\begin{array}{l}\text { Face mask practice } \\
\text { Yes } \\
\text { No }\end{array}$ & $\begin{array}{l}1092 \\
45\end{array}$ & $\begin{array}{l}96.0 \\
4.0\end{array}$ & $\begin{array}{l}482 \\
6\end{array}$ & $\begin{array}{l}98.8 \\
1.2\end{array}$ & .004 \\
\hline
\end{tabular}


The acceptance level were analysed between individuals who have worn facemask. As shown in Table 3, within 1574 individual who worn facemask, 1397 (88.8\%) individuals' facemask practice was acceptable while the reaming $177(11.2 \%)$ subject was perceived with unacceptable facemask practice. A significant relationship was found between facemask practice and the following variables; gender, ethnic, age group and session of visit to facility. Higher proportion of male from unacceptable group (66.1\%) and acceptable group (56.2\%) was observed compared to female $\chi^{2}(1)=6.306, p=.012$. As for ethnicity, higher number of Malay ethic from the unacceptable group $(68.4 \%)$ along with Malay ethnic from the acceptable group $(53.5 \%)$ was recorded compared to Non-Malay, $\chi 2(1)=13.95, \mathrm{p}<.001$. Similarly, lowrisk age group have both acceptable facemask practice (70.8\%) and unacceptable facemask practice $(58.2 \%)$ compared to high risk age group, $\chi^{2}(1)=11.74, p=.001$. Likewise, significantly more individuals $(73.8 \%)$ within the acceptable group and individuals $(80.8 \%)$ from the unacceptable group are visiting the facility during morning session compared with evening session, $\chi^{2}(1)=5.09, \mathrm{p}=0.024$. The unacceptable facemask practice was not contributed by the type of facemask as both medical grade and non-medical grade facemask groups had comparable proportion of individuals wearing it incorrectly at $11.5 \%$ (134) and $10.6 \%(43)$ respectively $\chi 2(1)=0.197, p=0.657$. Within 177 subjects with unacceptable facemask practice , 124 wore the mask loosely exposing either the nose, mouth or both while 48 was wearing the wrong side out, 4 wore cloth ( bandana, handkerchief ) while 1 wore eye mask as a facemask

Table 3 Demographic prolife between the acceptance of face mask practice $(n=1574)$

\begin{tabular}{|l|l|l|l|l|l|}
\hline & \multicolumn{2}{|l|}{ Acceptable $(\mathrm{n}=1397)$} & \multicolumn{2}{l|}{ Unacceptable $(\mathrm{n}=177)$} & \multirow{2}{*}{ P value } \\
\cline { 1 - 5 } $\begin{array}{l}\text { Demographic } \\
\text { characteristics }\end{array}$ & Frequency & Percent (\%) & Frequency & Percent (\%) & \\
\cline { 1 - 5 } $\begin{array}{l}\text { Gender } \\
\text { Male }\end{array}$ & 785 & 56.2 & 117 & 66.1 & .012 \\
Female & 612 & 43.8 & 60 & 33.9 & \\
\hline Ethnic & 748 & 53.5 & 121 & 68.4 & $<.001$ \\
Malay & & & & \\
\hline
\end{tabular}




\begin{tabular}{|l|l|l|l|l|l|}
\hline Non-Malay & 649 & 46.5 & 56 & 31.6 & \\
\hline Age group & & & & & .001 \\
Low-risk age group & 989 & 70.8 & 103 & 58.2 & \\
High-risk age group & 408 & 29.2 & 74 & 41.8 & \\
\hline Session of visit & & & & & .024 \\
Morning session' & 1018 & 73.8 & 143 & 80.8 & \\
Afternoon session & 379 & 26.2 & 34 & 19.2 & \\
\hline Category of facemask & 1036 & 74.2 & 134 & 75.7 & .657 \\
Medical Grade & 361 & 25.8 & 43 & 24.3 & \\
Non-Medical Grade & \multicolumn{2}{|l}{} & & \\
\hline
\end{tabular}

Simple logistic regression was used to screen demographic variable which contributed to unacceptable facemask practice. To reflect the risk of morbidity from Covid-19 infection , demographic profiles with low mortality rate such as female, non-Malay, low-risk age group , visit to facility in evening session was chooses as the reference. The result are presented on Table 4.

Table 4 The associated factor of unacceptable facemask practice by simple logistic regression

\begin{tabular}{|l|l|l|l|l|}
\hline $\begin{array}{l}\text { Demographic } \\
\text { characteristics }\end{array}$ & $\begin{array}{l}\text { Regression } \\
\text { coefficient }(\beta)\end{array}$ & $\begin{array}{l}\text { Crude odds ratio } \\
(95 \% \text { CI })\end{array}$ & Wald Statistic & P value \\
\hline $\begin{array}{l}\text { Gender } \\
\text { Female } \\
\text { Male }\end{array}$ & $\begin{array}{l}\text { Reference } \\
0.42\end{array}$ & $1.52(1.09,2.11)$ & 6.24 & .012 \\
\hline $\begin{array}{l}\text { Ethnic } \\
\text { Non-Malay }\end{array}$ & $\begin{array}{l}\text { Reference } \\
\text { Malay }\end{array}$ & 0.63 & 13.62 & \\
\hline $\begin{array}{l}\text { Age group } \\
\text { Low-risk age group }\end{array}$ & Reference & $1.34,2.62)$ & & $<.001$ \\
High-risk age group & 0.56 & $1.74(1.26,2.40)$ & & \\
\hline $\begin{array}{l}\text { Session of visit } \\
\text { Afternoon session }\end{array}$ & Reference & & 3.64 & .001 \\
Morning session & 0.382 & $1.47(0.99,2.17)$ & & \\
\hline $\begin{array}{l}\text { Type Of face Mask } \\
\text { Medical Grade }\end{array}$ & Reference & & 0.20 & .056 \\
Non-Medical Grade & 0.08 & $1.07(0.76,1.56)$ & & \\
\hline
\end{tabular}

CI: Confidence interval

The final binary logistic regression model for unacceptable facemask garbing practice was adjusted for gender, ethnic and age group (Table 5). 


\begin{tabular}{|c|c|c|c|c|}
\hline $\begin{array}{l}\text { Demographic } \\
\text { characteristics }\end{array}$ & $\operatorname{Adj} .(\beta)$ & $\begin{array}{l}\text { Adj. odds ratio } \\
(95 \% \mathrm{CI})\end{array}$ & Wald Statistic & $\mathrm{P}$ value \\
\hline $\begin{array}{l}\text { Gender } \\
\text { Female } \\
\text { Male }\end{array}$ & $\begin{array}{l}\text { Reference } \\
0.39\end{array}$ & $1.47(1.06,2.06)$ & 5.20 & .023 \\
\hline $\begin{array}{l}\text { Ethnic } \\
\text { Non-Malay } \\
\text { Malay } \\
\end{array}$ & $\begin{array}{l}\text { Reference } \\
0.78\end{array}$ & $2.18(1.55,3.08)$ & 19.72 & $<.001$ \\
\hline $\begin{array}{l}\text { Age group } \\
\text { Low-risk age group } \\
\text { High-risk age group }\end{array}$ & $\begin{array}{l}\text { Reference } \\
0.69\end{array}$ & $1.99(1.42,2.77)$ & 16.36 & $<.001$ \\
\hline
\end{tabular}

Adj.: Adjusted Regression coefficient, Adj. odds ratio: Adjusted odds ratio, CI: Confidence interval .The final model was obtained using backward linear regression model. Correlation matrix was checked for interaction between the variables was small. The 2-way interaction between the categorical was not significant. The Hosmer and Lemeshow test significant was $\mathrm{p}=.683$ indicating the model fit. Classification table (overall classification percentage $88.8 \%$ ) and the Area under the curve is 0.627 (95\% CI: 0.584-0.669) $\mathrm{p}=<.001$. The model can accurately discriminate $62.7 \%$ of the cases.

Male individuals had 1.47 times more likely to practice unacceptable facemask garbing (Odds Ratio; $\mathrm{OR}=1.47 ; 95 \% \mathrm{CI}, 1.06-2.06 ; \mathrm{p}=.023)$. Similarly, Malay ethnic individual are 2.18 times more likely to practice unacceptable facemask practice $(\mathrm{OR}=2.18 ; 95 \% \mathrm{CI}, 1.55-3.08$; $\mathrm{p}<.001)$.Finally, individuals from high-risk age group are 1.99 times more likely to practice unacceptable facemask practice $(\mathrm{OR}=2.18 ; 95 \% \mathrm{CI}, 1.42-2.77 ; \mathrm{p}<.001)$

\section{Discussion}

COVID-19 pandemic is an unprecedented medical event in the modern time ; to date, there is no known specific, effective, proven, pharmacological treatment and early efforts have focused on determining the clinical management, describing the spectrum of disease and tracking morbidity and mortality of SARS-CoV-2 infection [29, 30] . As no effective treatment is available, health care authorities have relied on public health management to mitigate local human-to-human transmission. By 25 April 2020 , most Asian countries (Case fatality rate; figure 1, total confirmed case per million; figure 2) , such as Indonesia $(8.39 \%, 30.02)$, 
Philippines $(6.63 \%, 65.63)$, China $(5.53,58.29)$, South Korea $(2.24 \%, 209.05)$, Thailand $(1.75 \%, 40.89)$, Singapore $(0.11 \%, 1910.66)$ and including Malaysia $(1.69,175.83)$ have reported substantial mortality impact [31]. South Korea was one of the hardest hit country during the initial outbreak but had managed to limit their COVID-19 outbreaks without lockdown. The success of Korean government could be attributed to extensive testing, rigorous contact tracing, and strict isolation as well as universally practices facemask in public[32] . Similarly, Hong Kong with world's highest prevalence of public facemask reported shorter influenza season ( 5 weeks versus $12-18$ weeks) during the first wave of the COVID-19 epidemic[33].

Figure 1 Case fatality rate of the ongoing Covid-19 pandemic , Apr 25,2020[31]

Case fatality rate of the ongoing COVID-19 pandemic

The Case Fatality Rate (CFR) is the ratio between confirmed deaths and confirmed cases.

During an outbreak of a pandemic the CFR is a poor measure of the mortality risk of the disease. We explain this in detail at OurWorldlnData.org/Coronavirus
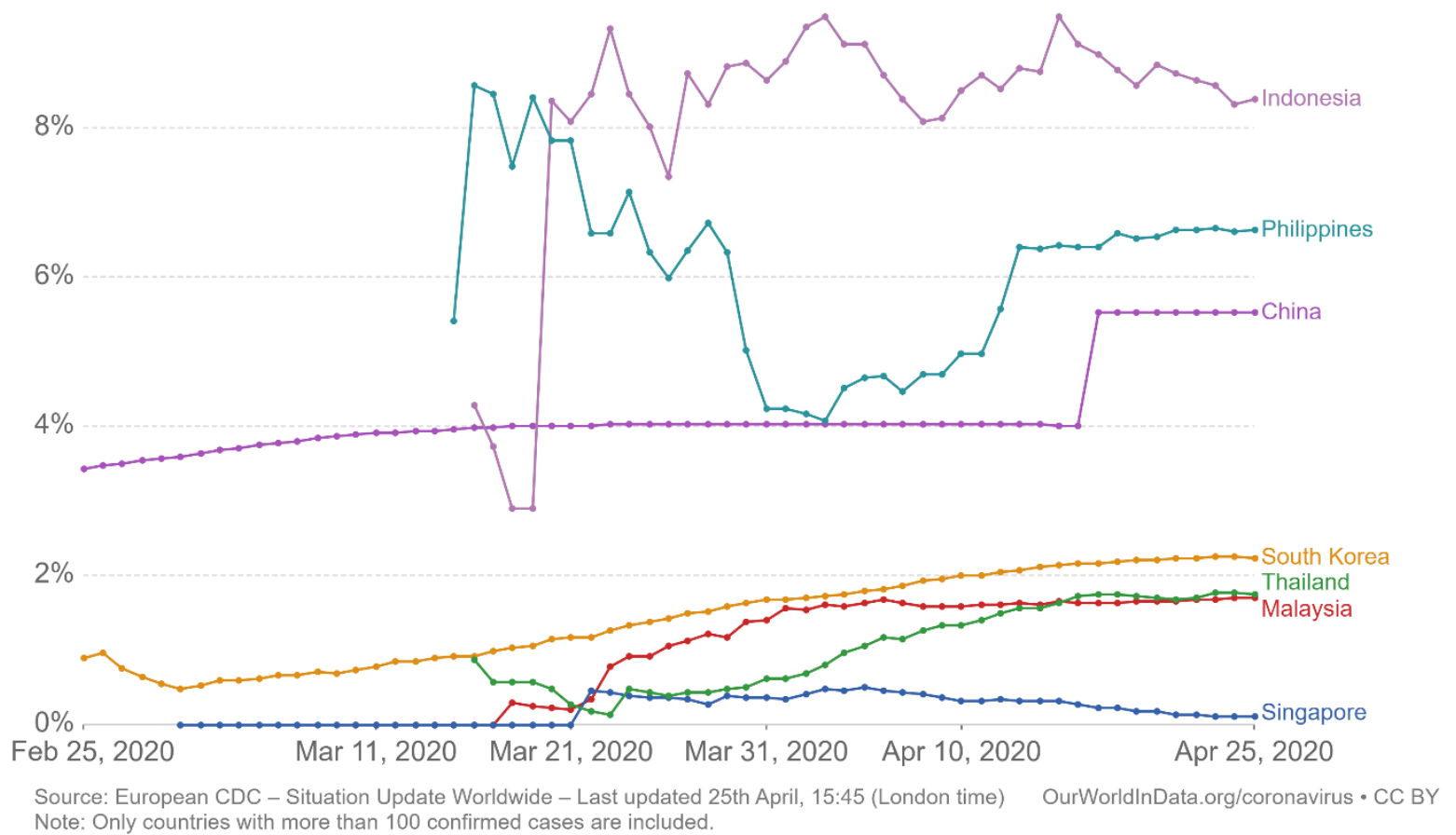
Figure 2 Total Covid-19 confirmed case per million people, Apr 25,2020[31]

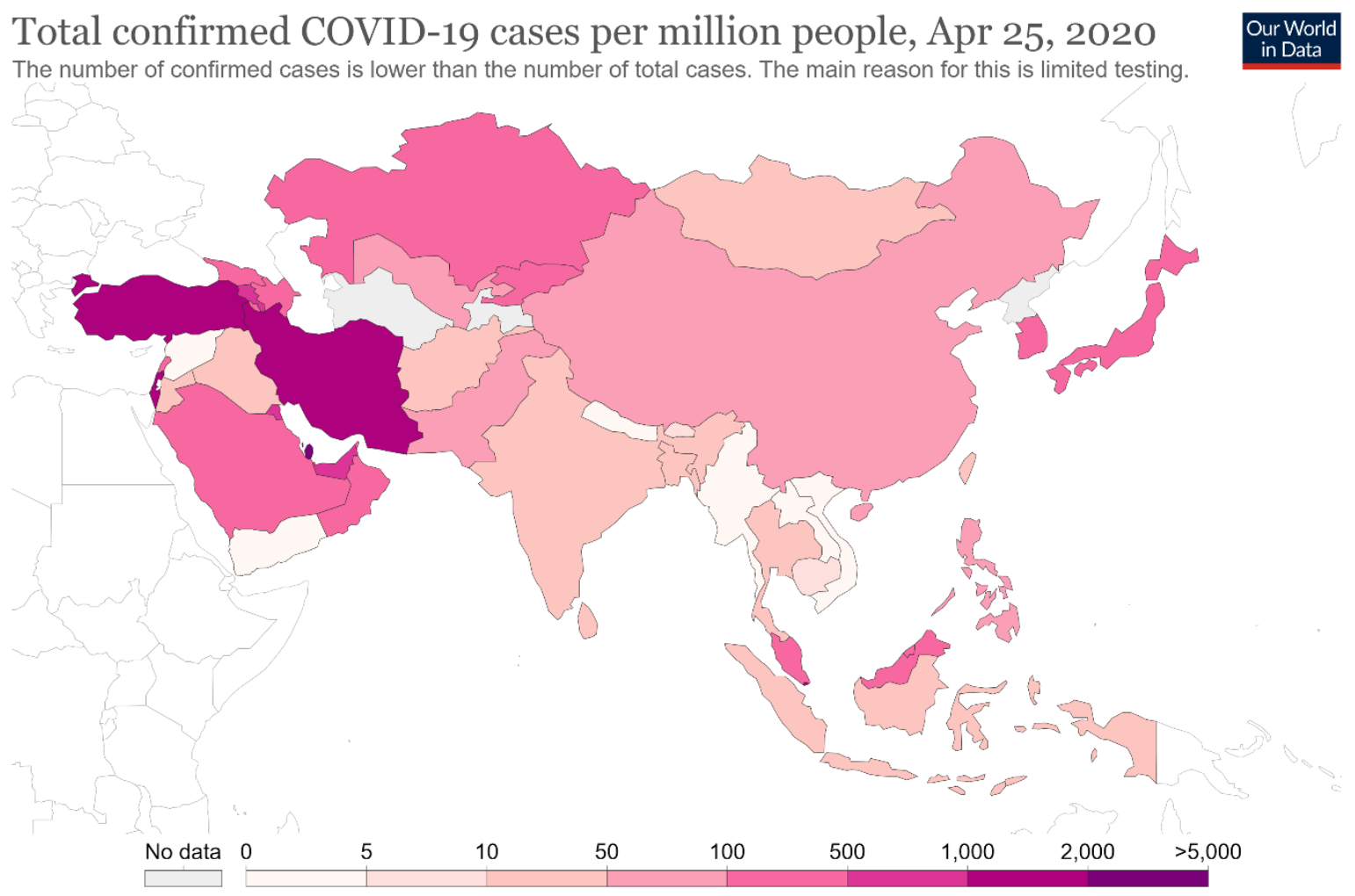

Source: European CDC - Situation Update Worldwide - Last updated 25th April, 15:45 (London time) OurWorldlnData.org/coronavirus • CC BY

Generally, health care authorities have recommended using facemask and practising social distance to reduce cross-transmission. This had led to a surge of demand for medical facemasks. Notably, China as the epicentre of the outbreak estimated the daily demand of facemask to be $>50$ million whereas the daily production has now dropped from 20 million to 15 million[33]. These have resulted in shortage of medical facemasks, which appears to be worldwide phenomena [17-19, 34]. Although Malaysia have reported shortage of facemask during the initial outbreak[35], the high prevalence (96.9\%) of individuals had worn facemask and majority $(72.0 \%)$ of them were using medical grade facemask indicating accessibility of facemask in local community . the wide spread use and availability of the facemask could be due to a few initiatives taken by the Malaysian government, namely ; importation on 10 million facemask from china during the acute shortage phase[36], increase in manufacturing 
and establishment of new manufacturing facility to increase in production capacity of local manufacturer [37, 38] and handling out 24.6 million facemask to Malaysian household[39].

Although we observed high percentage of medical grade facemask usage in both high-risk age group and low-risk age group, the high proportion among low-risk age group raises the question on the necessity of medical grade facemask use in community setting. The consensus recommended the use of facemask for vulnerable population particularly those older than 65 years and immunocompromised individuals. Evidence that facemasks can protect against infections in the community is relatively scare[40-42], as acknowledged by contrasting views on medical facemasks by governments and public health experts[20]. An epidemic forecasting models was used by Salim, Naomie, et al. to estimate the number of positive COVID-19 in Malaysia estimated that the peak will be on 19 April 2020 with an estimation of 5,637 positive cases [43], however 5,425 positive cases [44]were reported on the same date questioning the effectiveness of facemask in reducing infection. As evidence suggests COVID-19 could be transmitted through droplet $[45,46]$, surgical masks may be ineffective for prevention as they generally do not form a tight seal against the face skin and hence are not endorsed to protect people from airborne infectious as the infection could happen through the mucous membranes of the eyes[47].Nonetheless, two community based retrospective case-control studies in Hong Kong and China during previous 2003 SARS-CoV-1 outbreak reported that use of medical grade facemasks (surgical masks in both studies) was associated with at least $60 \%$ lower odds of contracting SARS [48, 49]. Besides, a simulation model by Eikenberry, Steffen E., et al. suggest use of facemasks by the general public could potentially restrain community transmission and reduce mortality rate due to Covid-19 pandemic by $24-65 \%$ [50] . currently , mounting evidence[51] and analysis[42, 52] supports the use of facemask as low-cost addition with social distancing and hand hygiene during the COVID-19 pandemic 
Despite the high prevalence of facemask usage among our population, we found that significantly high number of male, Malay ethic and high-risk age group have unacceptable facemask practice. The unacceptable facemask practice among this group raises concern as Males are more 1.85 times (OR: 1.85, 95\% CI 1.60-2.13) and high-risk age group are 18 times (OR: 18.82 , 95\% CI 7.20-41.55) more likely to die from COVID-19 [53] ; concurrently , mortality risk for both this group have been well established[9, 54, 55]. Although the current rate of mortality among Malay Ethnic is unknown, comorbidity among Malay ethic [56-59] predisposed them to increased hazard of death. Non-compliance to facemask practice such as loosely fitted facemask, exposing mouth and nose as observed by us have been reported as main concern in previous by other researches as well $[33,53,60]$; however the compliance could be improved through targeted public health education[40, 41].

While waiting for effective antiviral treatment against Covid-9, public health agencies should encourage personal hygiene behaviours such as facemask as adjuvant to social distancing and hand hygiene which have been proven to be effective in infection control[41, 61]. In addition, pre-emptive action needed to ensure compliance use of facemasks especially vulnerable populations to alleviate the stress on health care system.

Although our study presented the use of facemask among general population, our finding are not generalizable as the prevalence of facemask use from a single centre heavily really on local health care recommendation and the availability of commercial product on market. In addition, our population consist of individuals visiting hospital which is generally considered as high risk area for cross-infection and hence visitors could have taken extra precaution which could have skewed our observation. 


\section{Conclusion}

Ongoing Covid-19 infection in humans are unprecedented and no single strategy have proven to successfully contain the outbreak. Facing a worldwide public health emergency with limited effective clinical treatment, the inevitable impact public health is of paramount importance. Extensive use of facemasks coupled with comprehensive campaigns and other environmental hygiene measures is a vital epidemiology strategy which may help to mitigate the COVID-19 epidemic impact. In spite of contradicting opinion on the potential value of facemasks for general population use, targeted personal health education strategy to improve compliance to proper facemask practice among high risk population is needed to achieve maximal protective benefit.

\section{Acknowledgement}

Our study group would like to thank Director General, Ministry of Health Malaysia for approval to publish this research.

\section{Funding Statement.}

This research did not receive any specific grant from funding agencies in the public, commercial, or not-for-profit sectors.

\section{Conflicts of interest}

The authors declared that they have no conflict of interest

\section{References}

1. Cui, J., F. Li, and Z.-L. Shi, Origin and evolution of pathogenic coronaviruses. Nature reviews Microbiology, 2019. 17(3): p. 181-192. 
2. Lai, C.-C., et al., Severe acute respiratory syndrome coronavirus 2 (SARS-CoV-2) and corona virus disease-2019 (COVID-19): the epidemic and the challenges. International journal of antimicrobial agents, 2020: p. 105924.

3. Sohrabi, C., et al., World Health Organization declares global emergency: A review of the 2019 novel coronavirus (COVID-19). International Journal of Surgery, 2020.

4. Huang, C., et al., Clinical features of patients infected with 2019 novel coronavirus in Wuhan, China. The Lancet, 2020. 395(10223): p. 497-506.

5. Li, Q., et al., Early transmission dynamics in Wuhan, China, of novel coronavirus-infected pneumonia. New England Journal of Medicine, 2020.

6. Wang, W., J. Tang, and F. Wei, Updated understanding of the outbreak of 2019 novel coronavirus (2019-nCoV) in Wuhan, China. Journal of medical virology, 2020. 92(4): p. 441447.

7. Ren, L.-L., et al., Identification of a novel coronavirus causing severe pneumonia in human: a descriptive study. Chinese medical journal, 2020.

8. Cascella, M., et al., Features, evaluation and treatment coronavirus (COVID-19), in StatPearls [Internet]. 2020, StatPearls Publishing.

9. Baud, D., et al., Real estimates of mortality following COVID-19 infection. The Lancet infectious diseases, 2020.

10. Wu, P., et al., Real-time tentative assessment of the epidemiological characteristics of novel coronavirus infections in Wuhan, China, as at 22 January 2020. Eurosurveillance, 2020. 25(3): p. 2000044.

11. Yang, J., et al., Prevalence of comorbidities in the novel Wuhan coronavirus (COVID-19) infection: a systematic review and meta-analysis. International Journal of Infectious Diseases, 2020.

12. Guo, Y.-R., et al., The origin, transmission and clinical therapies on coronavirus disease 2019 (COVID-19) outbreak-an update on the status. Military Medical Research, 2020. 7(1): p. 110.

13. Kucharski, A.J., et al., Early dynamics of transmission and control of COVID-19: a mathematical modelling study. The lancet infectious diseases, 2020.

14. Bai, Y., et al., Presumed asymptomatic carrier transmission of COVID-19. Jama, 2020.

15. Hu, Z., et al., Clinical characteristics of 24 asymptomatic infections with COVID-19 screened among close contacts in Nanjing, China. Science China Life Sciences, 2020: p. 1-6.

16. Holland, M., D.J. Zaloga, and C.S. Friderici, COVID-19 Personal Protective Equipment (PPE) for the emergency physician. Visual Journal of Emergency Medicine, 2020. 19: p. 100740.

17. Rowan, N.J., et al., Challenges and solutions for addressing critical shortage of supply chain for personal and protective equipment (PPE) arising from Coronavirus disease (COVID19) pandemic-case study from the Republic of Ireland.. 2018.

18. Rowan, N.J. and J.G. Laffey, Challenges and solutions for addressing critical shortage of supply chain for personal and protective equipment (PPE) arising from Coronavirus disease (COVID19) pandemic-case study from the Republic of Ireland. Science of the Total Environment, 2020: p. 138532.

19. Bhattacharya, S., M.M. Hossain, and A. Singh, Addressing the shortage of personal protective equipment during the COVID-19 pandemic in India-A public health perspective.

20. Feng, S., et al., Rational use of face masks in the COVID-19 pandemic. The Lancet Respiratory Medicine, 2020.

21. Organization, W.H., Rational use of personal protective equipment for coronavirus disease (COVID-19): interim guidance, 27 February 2020. 2020, World Health Organization.

22. Organization, W.H., Rational use of personal protective equipment for coronavirus disease ( COVID-19) and considerations during severe shortages: interim guidance, 6 April 2020. 2020, World Health Organization. 
23. Brienen, N.C., et al., The effect of mask use on the spread of influenza during a pandemic. Risk Analysis: An International Journal, 2010. 30(8): p. 1210-1218.

24. Gunasekaran, G.H., et al., Impact of chemotherapy schedule modification on breast cancer patients: a single-centre retrospective study. International Journal of Clinical Pharmacy, 2020.

25. Horng, W.-B., C.-P. Lee, and C.-W. Chen, Classification of age groups based on facial features. 淡江理工學刊, 2001. 4(3): p. 183-192.

26. COVID, C. and R. Team, Severe outcomes among patients with coronavirus disease 2019 (COVID-19)-United States, February 12-March 16, 2020. MMWR Morb Mortal Wkly Rep, 2020. 69(12): p. 343-346.

27. Wu, J.T., et al., Estimating clinical severity of COVID-19 from the transmission dynamics in Wuhan, China. Nature Medicine, 2020: p. 1-5.

28. Zhou, F., et al., Clinical course and risk factors for mortality of adult inpatients with COVID-19 in Wuhan, China: a retrospective cohort study. The Lancet, 2020.

29. Chen, L., et al., Convalescent plasma as a potential therapy for COVID-19. The Lancet Infectious Diseases, 2020. 20(4): p. 398-400.

30. Cortegiani, A., et al., A systematic review on the efficacy and safety of chloroquine for the treatment of COVID-19. Journal of critical care, 2020.

31. Max Roser, H.R., Esteban Ortiz-Ospina and Joe Hasell, Coronavirus Disease (COVID-19). Our World in Data, 2020.

32. Cheng, K.K., T.H. Lam, and C.C. Leung, Wearing face masks in the community during the COVID-19 pandemic: altruism and solidarity. The Lancet, 2020.

33. Chan, K.H. and K.-Y. Yuen, COVID-19 epidemic: disentangling the re-emerging controversy about medical facemasks from an epidemiological perspective. International Journal of Epidemiology, 2020.

34. Mahase, E., Novel coronavirus: Australian GPs raise concerns about shortage of face masks. BMJ, 2020. 368: p. m477.

35. Urgent need to address shortage of face masks for health personnel, in New Straits Times. 2020, Media Prima Group: Online.

36. Bernama, 10m face masks to be brought in from China - Works Minister, in The Edge. 2020, The Edge Communications Sdn. Bhd.

37. Star, T., Manufacturers told to increase face mask production, says minister, in TheStarTv. 2020, Star Media Group Berhad https://www.thestartv.com/v/manufacturers-told-toincrease-face-mask-production-says-minister. Date Acessed [ 26-04-2020]

38. Glove, condom makers turn face mask producers for Covid-19 crisis, in FMT news. 2020, Reuters: https://www.freemalaysiatoday.com/category/nation/2020/04/10/glove-condommakers-turn-face-mask-producers-for-covid-19-crisis/. Date Acessed [ 26-04-2020]

39. Ngui, Y., Malaysia to Give Out Masks to Households as Guidance Shifts, in Bloomberg. 2020, Bloomberg L.P: https://www.bloomberg.com/news/articles/2020-04-08/malaysia-to-giveout-masks-to-households-as-guidance-shifts. Date Acessed [ 26-04-2020]

40. Jefferson, T., et al., Physical interventions to interrupt or reduce the spread of respiratory viruses: systematic review. Bmj, 2009. 339: p. b3675.

41. Maclntyre, C.R., et al., Face mask use and control of respiratory virus transmission in households. Emerging infectious diseases, 2009. 15(2): p. 233.

42. MacIntyre, C.R. and A.A. Chughtai, Facemasks for the prevention of infection in healthcare and community settings. Bmj, 2015. 350: p. h694.

43. Salim, N., et al., COVID-19 epidemic in Malaysia: Impact of lock-down on infection dynamics. medRxiv, 2020.

44. Jr, J.K., Covid-19: 36 new cases, no deaths for first time in a month, in The star. 2020, Star Media Group Berhad: https://www.thestar.com.my/news/nation/2020/04/20/covid-19-36new-cases-no-deaths-for-first-time-in-a-month.Date Acessed [ 26-04-2020] 
45. Wang, C., et al., A novel coronavirus outbreak of global health concern. The Lancet, 2020. 395(10223): p. 470-473.

46. Zhu, N., et al., A novel coronavirus from patients with pneumonia in China, 2019. New England Journal of Medicine, 2020.

47. Lee, S.-A., et al., Particle size-selective assessment of protection of European standard FFP respirators and surgical masks against particles-tested with human subjects. Journal of healthcare engineering, 2016. 2016.

48. Wu, J., et al., Risk factors for SARS among persons without known contact with SARS patients, Beijing, China. Emerging infectious diseases, 2004. 10(2): p. 210.

49. Lau, J.T., et al., SARS transmission, risk factors, and prevention in Hong Kong. Emerging infectious diseases, 2004. 10(4): p. 587.

50. Eikenberry, S.E., et al., To mask or not to mask: Modeling the potential for face mask use by the general public to curtail the COVID-19 pandemic. Infectious Disease Modelling, 2020.

51. Howard, J., et al., Face masks against COVID-19: an evidence review. 2020.

52. Greenhalgh, T., et al., Face masks for the public during the covid-19 crisis. BMJ, 2020. 369.

53. Caramelo, F., N. Ferreira, and B. Oliveiros, Estimation of risk factors for COVID-19 mortalitypreliminary results. medRxiv, 2020.

54. Jin, J.-M., et al., Gender differences in patients with COVID-19: Focus on severity and mortality. medRxiv, 2020.

55. Wei, X., et al., Sex Differences in Severity and Mortality Among Patients With COVID-19: Evidence from Pooled Literature Analysis and Insights from Integrated Bioinformatic Analysis. arXiv preprint arXiv:2003.13547, 2020.

56. Tan, P.Y., An intervention programme for weight management in overweight and obese Malaysian adults. 2020, University of Nottingham.

57. Cheah, Y.K. and D. Meltzer, Ethnic Differences in Participation in Medical Check-ups Among the Elderly: Evidence from Malaysia. Journal of general internal medicine, 2020: p. 1-7.

58. Wong, P.L., et al., The effects of age on clinical characteristics, hospitalization and mortality of patients with influenza-related illness at a tertiary care centre in Malaysia. Influenza and Other Respiratory Viruses, 2020.

59. Ahmad, W., et al. Cardiovascular Risk Factors in Rural Malays and Aborigines in Perak, Malaysia; An Alarming Situation. in Med. Forum. 2018.

60. Runge, P., Not all Face Masks are Created Equal-What is Best for You. Dental Assistant. ProQuest Health and Medical Complete 2005; 74, 2005. 4.

61. Lau, J., et al., Perceptions related to bird-to-human avian influenza, influenza vaccination, and use of face mask. Infection, 2008. 36(5): p. 434-443. 